\title{
Cataract Surgery combined with excimer laser trabeculotomy to lower intraocular pressure: effectiveness dependent on preoperative IOP
}

\author{
Marc Töteberg-Harms ${ }^{1,2^{*}}$, James VM Hanson ${ }^{2}$ and Jens Funk ${ }^{2}$
}

\begin{abstract}
Background: Cataract surgery combined with excimer laser trabeculotomy (phaco-ELT) can reduce intraocular pressure (IOP). The aim of this study was to evaluate the effect of phaco-ELT on IOP in patients as a function of preoperative IOP.
\end{abstract}

Methods: Patients with open-angle glacuoma or ocular hypertension who received phaco-ELT between 01/2008 and 10/2009 were included. Patients were assigned based on preoperative IOP either to the study group $(\leq 21 \mathrm{mmHg}$ ) or control group ( $>21 \mathrm{mmHg}$ ) in this IRB-approved, prospective, consecutive case series. Visual Acuity, IOP, and number of anti-glaucoma drugs (AGD) were recorded at baseline and 12 months after phaco-ELT. Any postoperative complications were also recorded.

Results: 64 eyes of 64 patients (76.5 \pm 9.4 years) were included. Baseline IOP was $19.8 \pm 5.3 \mathrm{mmHg}$ (AGD $2.4 \pm 1.1$ ) for all eyes, $16.5 \pm 2.9 \mathrm{mmHg}$ (AGD $2.5 \pm 1.0$ ) for the study group, and $25.8 \pm 2.9 \mathrm{mmHg}$ (AGD 2.2 \pm 1.4 ) for the control group. Across the two groups, IOP was reduced by $4.5 \pm 5.9 \mathrm{mmHg}(-23.0 \%, \mathrm{p}<0.001)$ and AGD by $0.9 \pm 1.5$ $(-38.9 \%, \mathrm{p}<0.001)$. For the study group IOP was reduced by $1.9 \pm 4.4 \mathrm{mmHg}(-11.5 \%, \mathrm{p}=0.012)$ and AGD by $1.1 \pm 1.4(-42.9 \%, p<0.001)$, and for the control group by $9.5 \pm 5.4 \mathrm{mmHg}(-36.6 \%, p<0.001)$ and $A G D$ by $0.7 \pm 1.6$ $(-29.5 \%, p=0.085)$. There were no serious postoperative complications such as endophthalmitis, significant hyphema, or a severe fibrinous reaction of the anterior chamber.

Conclusions: IOP remained significantly reduced from baseline 12 months after phaco-ELT regardless of preoperative IOP levels, with no major complications. The IOP reduction remained constant over the entire followup. Hence, phaco-ELT can be considered in glaucoma and ocular hypertensive patients whenever cataract surgery is performed, in order to further reduce IOP or to reduce the requirement for IOP-reducing medications.

Keywords: Cataract, Cataract surgery, Extracapsular cataract extraction, Phacoemulsification, Glaucoma, Glaucoma surgery, Excimer laser trabeculotomy, Excimer laser trabeculostomy, Trabecular meshwork, Primary open angle glaucoma, Ocular hypertension

\section{Background}

Glaucoma is a widespread disease leading to progressive loss of visual function and remains one of the leading causes of irreversible blindness around the world. In managing glaucoma patients, the goal of IOP reduction remains the only therapeutic approach supported by a significant evidence base [1-6]. Treatment often begins with topical medications.

\footnotetext{
* Correspondence: MarcToeteberg@aol.com
'Massachusetts Eye \& Ear Infirmary, Harvard Medical School, 243 Charles

'Massachusetts Eye \& Ear Infirmary, Harvard Medical School, 243 Charles Street, Boston, MA 02114, USA

${ }^{2}$ Department of Ophthalmology, UniversityHospital Zurich, Frauenklinikstrasse 24, Zurich, 8091, Switzerland
}

If IOP remains insufficiently controlled, several surgical procedures are available in order to further reduce IOP. Trabeculectomy remains the gold standard in glaucoma surgery [7] and is very effective in long-term reduction of IOP. However, trabeculectomy and other surgical glaucoma procedures have substantial disadvantages [8]. IOP elevation is usually caused by reduced drainage of aqueous humor, whilst aqueous production remains constant. The main location of outflow resistance is likely to be the juxtacanalicular trabecular meshwork (TM) $[9,10]$. Therefore, the most physiologically feasible goal of any surgical procedure to reduce IOP is 
to improve trabecular outflow. Excimer laser trabeculotomy (or excimer laser trabeculostomy, ELT) ab interno is one minimally invasive surgical technique to reduce IOP in patients with glaucoma or ocular hypertension. ELT enhances aqueous humor outflow into Schlemm's canal and its drainage against the episcleral vein pressure by creating channels from the anterior chamber through the TM and inner wall of Schlemm's canal [11-24]. It is not usually possible to reduce IOP to the same level as achieved through fistulating surgery. However, the ELT technique is one that can be quickly acquired by ophthalmic surgeons, especially cataract surgeons. ELT is relatively safe in combination with cataract surgery and can lower IOP to a greater degree than that achieved by cataract extraction alone [20]. The potential to reduce IOP in patients with elevated pre-operative IOP $(>21 \mathrm{mmHg}$ ) has been previously investigated. However, the comparative effectiveness of combined phacoemulsification and ELT in patients with lower pre-operative IOP remains unclear. The aim of this study was therefore to evaluate whether phaco-ELT is also effective in lowering the IOP in eyes with IOP $\leq 21 \mathrm{mmHg}$. To investigate this question two groups of patients were evaluated: one with a preoperative IOP of $\leq 21 \mathrm{mmHg}$ (study group), and a second with a preoperative IOP of $>21 \mathrm{mmHg}$ (control group).

\section{Methods}

Included in this prospective, single-center case-series were consecutive patients who underwent clear cornea extracapsular cataract extraction by phacoemulsification and intracapsular lens implantation combined with ELT (phaco-ELT) between 01/2008 and 10/2009. If both eyes of a patient underwent phaco-ELT, only the eye that was operated first was included in the study; thus, 9 eyes were excluded. Patients were followed-up at 12 months \pm 2 weeks after the procedure. All subjects were recruited from the ophthalmological out-patient department and gave prior written informed consent. The study was approved by the local ethics committee (Ethics Committee of the Canton Zurich, KEK-ZH-Nr. 881, 06/07/2009) and adhered to the tenets of the Declaration of Helsinki and local law. The study is registered in the clinical trials registry of the U.S. National Institutes of Health (http://www. clinicaltrials.gov, NCT01194310). Intraocular pressure (using Goldmann applanation tonometry), best corrected visual acuity (BCVA, using Snellen charts), slit lamp biomicroscopy of the anterior and posterior segment as well as glaucoma medication history were documented by one examiner (M. T.-H.). The indications for a combined phaco-ELT intervention were the presence of a visually significant cataract (BCVA less than or equal to 0.5 Snellen) and a moderately elevated IOP in the absence of medical therapy, or a moderate cataract (BCVA less than or equal to 0.8 Snellen) and uncontrolled IOP despite medical therapy.

\section{Inclusion/exclusion criteria}

Inclusion criteria were a diagnosis of ocular hypertension or manifest glaucoma with typical glaucomatous cupping of the optic disc, visual field changes, or both, together with an open iridocorneal angle (grade 3 or 4 on the Shaffer scale [25]). Patients with advanced glaucoma (i.e., fixation-threatening visual-field defects) or with an IOP $\geq 35 \mathrm{mmHg}$ were excluded. Patients with a history of optic neuropathies other than glaucoma were also excluded.

\section{Surgical procedure}

All surgeries were performed by the same surgeon (J. F.). A standard clear-cornea phacoemulsification and intracapsular lens implantation (Alcon MA 50 BM, Alcon Inc., Hünenberg, Switzerland) was performed. Immediately afterwards, a medical miosis was induced by acetylcholine chloride (Miochol) and the anterior chamber was deepened with viscoelastic (sodium hyaluronate, Healon). An endoscopically-guided photoablative laser operating at a wavelength of $308 \mathrm{~nm}$ (excimer laser, AIDA, TUI-Laser, Munich, Germany) was used to create ten microperforations (ELT channels) into the trabecular meshwork spread over an area of $90^{\circ}$. Each ELT channel was approximately $0.2 \mathrm{~mm}$ in diameter. Further details of the laser device are provided in Table 1. In order to transmit adequate sub-threshold energy of the laser to the target tissue, the instrument tip had to touch the TM (see Figure 1). After laser application a formation of bubbles was seen together with a small retrograde bleeding, indicating the perforation of the trabecular meshwork and the inner wall of Schlemm's canal (see Figure 2). In all patients the bleeding resolved spontaneously. At the end of the surgical procedure, the viscoelastic was washed out of the anterior chamber and the globe was pressurized to approximately $15 \mathrm{mmHg}$. The paracentesis and clear corneal incision were hydrated with sterile balanced salt solution (BSS). Cefazolin and Dexamethasone were injected subconjunctivally at the end of the procedure. Intracameral endophthalmitis

\section{Table 1 Technical data of the AIDA excimer laser}

\begin{tabular}{ll}
\hline Laser type & XeCl excimer laser, laser class 4 \\
\hline Wavelength & $308 \mathrm{~nm}$ \\
Cooling & Air \\
Pulse energy & $1.2 \mathrm{~mJ}$ at fiber tip \\
Pulse duration & $60 \mathrm{~ns}$ \\
Repetition rate & $20 \mathrm{~Hz}$ \\
Laser spot size & $200 \mu \mathrm{m}$ \\
Cannula diameter & $500 \mu \mathrm{m}$ \\
Cannula material & Stainless steel \\
Length of fiber & $2,000 \mathrm{~mm}$ \\
\hline
\end{tabular}




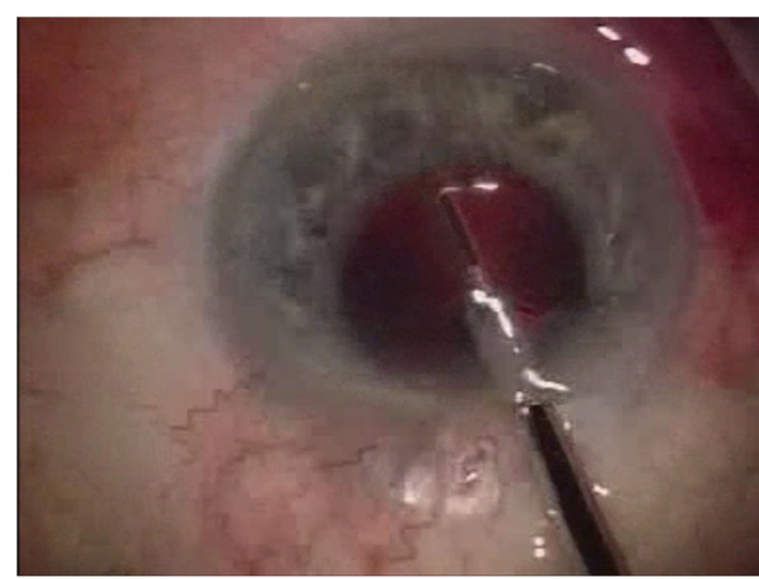

Figure 1 Under endoscopic guidance, ten laser spots were applied into the trabecular meshwork spread over an area of $\mathbf{9 0 ^ { \circ }}$. At the point of laser transmission, the probe is in direct contact with the trabecular meshwork.

prophylaxis was not used because at the time of the study no commercially available antibiotic solution was certified or approved for this purpose, and because of the risk of serious side effects (e.g. toxic anterior segment syndrome, anaphylaxis in patients with a history of penicillin allergy). Combined Tobramycin and Dexamethasone ointment was applied and the eye was covered with an eye patch overnight. From the first postoperative day, Tobramycin and Dexamethasone eye drops (q.i.d.) and Tobramycin and Dexamethasone ointment (at bedtime) were applied for 2 weeks. After the second week, only the eye drops (three times daily) were applied and reduced weekly by one drop.

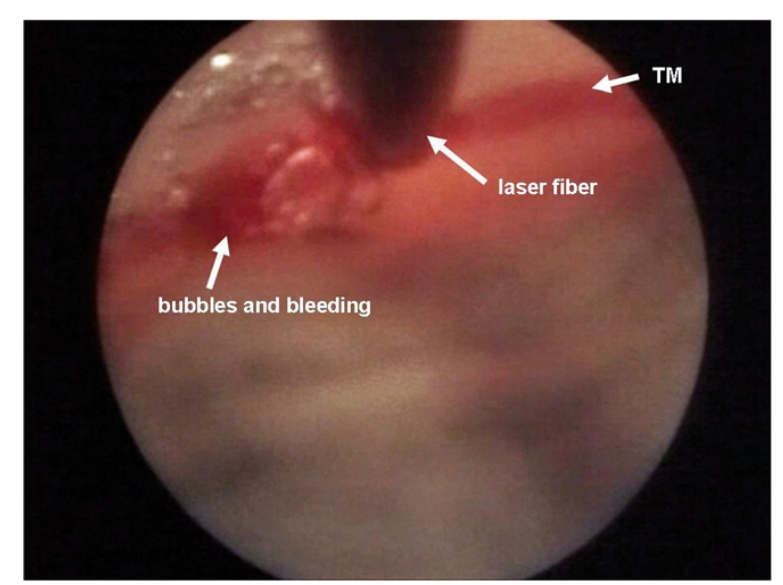

Figure 2 After laser application a formation of bubbles could be seen, together with a small retrograde bleeding.

\section{Study endpoints}

Primary study endpoints were IOP and number of antiglaucoma drugs (AGD) taken. Secondary study endpoints were BCVA, intra- and postoperative complications, and the requirement for subsequent glaucoma surgery.

\section{Statistical analyses}

Descriptive statistics for quantitative variables such as mean, standard deviation, 95\% confidence interval and relative frequencies for qualitative variables were calculated for all study eyes (without dropouts) and for the two subgroups separately - one with a preoperative IOP of $\leq 21 \mathrm{mmHg}$ (study group) and one with a preoperative IOP of $>21 \mathrm{mmHg}$ (control group). Data are given as arithmetic mean \pm standard deviation. A student's $t$ test was used for testing significant changes in IOP, BCVA and number of AGD. The significance level was defined by $\mathrm{p}<0.05$. For statistics (e.g. percentage change), BCVA was transformed to $\operatorname{logMAR}$ values and retransformed into Snellen for reporting of the results $[26,27]$. Additionally, the number of patients that met the success criteria was calculated. Statistical analyses were conducted in SPSS software version 19.0.0 for Macintosh (IBM Corporation, New York, NY, USA).

\section{Definition of success and failure}

Success was defined based on the criteria from the Tube Versus Trabeculectomy study (TVT study) [28] as postoperative IOP below or equal to $21 \mathrm{mmHg}$ and IOP reduction of at least $20 \%$. In addition, the number of AGD postoperatively had to be less than or equal to that recorded preoperatively. Subsequent surgery within the follow-up period (12 months) due to insufficient IOP reduction at the initial intervention was classified as treatment failure.

\section{Results}

In total, 64 eyes of 64 consecutive patients with a mean age of $76.5 \pm 9.4$ years were included. The demographical data for all study eyes and the two groups is shown in Table 2.

For all study eyes mean preoperative IOP was $19.8 \pm$ $5.3 \mathrm{mmHg}$ (95\% confidence interval (CI) 18.4 - 21.2) and the mean number of prescribed AGD was $2.4 \pm 1.1$ (95\% CI 2.1 - 2.7). After phaco-ELT, mean IOP was $15.2 \pm 4.4 \mathrm{mmHg}(95 \% \mathrm{CI} 14.1-16.4)$ and an average of $1.5 \pm 1.4$ AGD (95\% CI 1.1 - 1.8) were prescribed (see Table 3). Comparing the preoperative and postoperative IOP, there was a reduction of $4.5 \pm 5.9 \mathrm{mmHg}(-23.0 \%$, $95 \%$ CI $3.0-6.1, \mathrm{p}<0.001)$ and a reduction in the number of required AGD of $0.9 \pm 1.5(-38.9 \%, 95 \%$ CI $0.5-$ 1.3, $\mathrm{p}<0.001$; see Table 4). 
Table 2 Demographic data

\begin{tabular}{|c|c|}
\hline Number of study eyes & $\begin{array}{l}64 \text { ( } 26 \text { right and } 40 \text { left eyes) } \\
\text { from } 64 \text { patients }\end{array}$ \\
\hline mean age & $76.5 \pm 9.4$ years \\
\hline gender & $\begin{array}{l}22 \text { males }(34.4 \%) / 42 \text { females } \\
(65.6 \%)\end{array}$ \\
\hline Diagnosis: & no. of patients \\
\hline primary open angle glaucoma & $21(32.8 \%)$ \\
\hline pseudoexfoliative glaucoma & $37(57.8 \%)$ \\
\hline normal-tension glaucoma & $2(3.1 \%)$ \\
\hline ocular hypertension & $4(6.3 \%)$ \\
\hline \multicolumn{2}{|l|}{$\begin{array}{l}\text { Study group (IOP pre phaco-ELT } \\
\leq 21 \mathrm{mmHg} \text { ): }\end{array}$} \\
\hline Number of eyes & $\begin{array}{l}40 \text { (13 right and } 27 \text { left eyes) from } \\
40 \text { patients }\end{array}$ \\
\hline mean age & $79.2 \pm 7.4$ years \\
\hline gender & $\begin{array}{l}15 \text { males ( } 37.5 \%) / 25 \text { females } \\
(62.5 \%)\end{array}$ \\
\hline \multicolumn{2}{|c|}{$\begin{array}{l}\text { Control group (IOP pre phaco-ELT } \\
>21 \mathrm{mmHg} \text { ): }\end{array}$} \\
\hline Number of eyes & $\begin{array}{l}24 \text { ( } 11 \text { right and } 13 \text { left eyes) from } \\
24 \text { patients }\end{array}$ \\
\hline mean age & $74.9 \pm 12.2$ years \\
\hline gender & 9 males $(37.5 \%) / 15$ females $(62.5 \%$ \\
\hline
\end{tabular}

Analyzing the study group (preoperative IOP $\leq 21 \mathrm{mmHg}$ ), the mean preoperative IOP was $16.5 \pm$ $2.9 \mathrm{mmHg}(95 \%$ CI $15.5-17.5)$ and a mean of $2.5 \pm 1.0$ AGD (95\% CI 2.2 - 2.8) was recorded before treatment. After phaco-ELT, mean IOP was $14.6 \pm 3.7 \mathrm{mmHg}(95 \%$ CI $13.4-15.9)$ and an average of $1.4 \pm 1.3$ AGD (95\% CI 1.0 - 1.8) were required (see Table 3). Comparing the preoperative and postoperative IOP, there was a reduction of $1.9 \pm 4.4 \mathrm{mmHg}(-11.5 \%, 95 \%$ CI $0.4-3.3$, $\mathrm{p}=0.012$ ), and a reduction in the number of prescribed AGD of $1.1 \pm 1.4(-42.9 \%, 95 \%$ CI $-0.6-1.5, \mathrm{p}<0.001$; see Table 4).

Analyzing the control group (preoperative IOP $>21 \mathrm{mmHg}$ ), the mean preoperative IOP was $25.8 \pm$ $2.9 \mathrm{mmHg}$ (95\% CI 24.5 - 27.1) and the mean of prescribed AGD was $2.2 \pm 1.4$ (95\% CI 1.6 - 2.8). After phaco-ELT the mean IOP in this group was $16.4 \pm$ $5.4 \mathrm{mmHg}(95 \% \mathrm{CI} 13.9-18.9)$ and an average of $1.6 \pm$ 1.5 AGD (95\% CI $0.9-2.2)$ were required (see Table 3 ). Comparing the preoperative and postoperative IOP, there was a reduction of $9.5 \pm 5.4 \mathrm{mmHg}(-36.6 \%, 95 \%$ CI $6.9-12.0, \mathrm{p}<0.001)$, and a reduction in the number of required AGD of $0.7 \pm 1.6(-29.5 \% 95 \%$ CI $0.1-1.4$, $\mathrm{p}=0.085$; see Table 4).

Preoperative BCVA was $0.4 \pm 0.2$ Snellen, which improved significantly after cataract surgery $(\mathrm{p}<0.001)$ for all study eyes to $0.7 \pm 0.3$ Snellen and in the study and control groups from $0.4 \pm 0.2$ to $0.7 \pm 0.3$ and from $0.4 \pm$ 0.3 to $0.8 \pm 0.3$, respectively (see Table 3 ).

Seven eyes needed further glaucoma surgery to control the IOP within the 12-month follow-up period and were thus classified as treatment failures when calculating the success-rate (see Table 5). After the follow-up period of 12 months 30 out of 64 eyes (46.9\%) met the criteria of success. In the study group 15 out of 40 eyes (37.5\%) and in the control group 15 out of 24 eyes (62.5\%) met the criteria of success.

Only a few patients showed a mild anterior chamber reaction, as is often seen after cataract surgery. No patients suffered from serious postoperative complications such as endophthalmitis, significant hyphema, or a severe fibrinous reaction of the anterior chamber.

\section{Discussion}

The study confirmed a reduction in IOP, regardless of preoperative value, and a reduction in AGD after the follow-up period of 12 months. IOP for all study eyes was reduced from $19.8 \pm 5.3 \mathrm{mmHg}$ at baseline by $-4.5 \pm$ $5.9 \mathrm{mmHg}(-23.0 \% ; \mathrm{P}<0.001)$ and at the same time the average number of required AGD was reduced from 2.4 \pm 1.1 by nearly one medication $(-0.9 \pm 1.5 ;-38.9 \%$; $\mathrm{P}<0.001$ ). The study group (preoperative IOP $\leq 21 \mathrm{mmHg}$ ) showed a reduction in IOP from $16.5 \pm 2.9 \mathrm{mmHg}$ at baseline of $-1.9 \pm 4.4 \mathrm{mmHg}(-11.5 \% ; \mathrm{P}=0.012)$, whilst at the same time AGD could be reduced from $2.5 \pm 1.0$ by $-1.1 \pm 1.4(-42.9 \% ; \mathrm{P}<0.001)$. The control group (preoperative IOP $>21 \mathrm{mmHg}$ ) showed a reduction in IOP from $25.8 \pm 2.9 \mathrm{mmHg}$ at baseline of $-9.5 \pm 5.4 \mathrm{mmHg}$ $(-36.6 \% ; P<0.001)$, whilst at the same time AGD could be reduced from $2.2 \pm 1.4$ by $-0.7 \pm 1.6 \quad(-29.5 \%$; $P=0.085)$. The reduction of AGD in the control group tended toward, but did not reach, statistical significance.

Excimer laser trabeculectomy is easy to perform at the end of a clear-cornea extracapsular cataract extraction by phacoemulsification. Duration of cataract surgery is only prolonged by $2-3$ minutes for the excimer laser trabeculotomy and, as the same clear corneal incision as for phacoemulsification is also used for ELT, no additional incision is required. For an experienced cataract surgeon, ELT is usually a very easy technique to learn. In general, dealing with the endoscope is very simple, and identification of TM is much simpler with the endoscope than with a gonioscopy lens at the slit lamp.

Using energy with a wavelength of $308 \mathrm{~nm}$, the trabecular meshwork is gently ablated and microperforations between the anterior chamber and Schlemm's canal are created (ELT channels) $[16,29,30]$. There are almost no thermal side effects or damage of the outer wall of Schlemm's canal. During ablation, the TM tissue is vaporized into gas; the expanding gas has the effect of cooling the tissue and thus limiting thermal damage. 
Table 3 Statistical data of BCVA (Snellen), IOP (mmHg) and AGD (numbers) pre and post phaco-ELT

\begin{tabular}{|c|c|c|c|c|c|c|c|c|c|c|c|c|}
\hline & \multicolumn{4}{|c|}{ BCVA } & \multicolumn{4}{|c|}{ IOP } & \multicolumn{4}{|c|}{ AGD } \\
\hline & \multicolumn{2}{|c|}{ Pre } & \multicolumn{2}{|c|}{ Post } & \multicolumn{2}{|c|}{ Pre } & \multicolumn{2}{|c|}{ Post } & \multicolumn{2}{|c|}{ Pre } & \multicolumn{2}{|c|}{ Post } \\
\hline & Mean \pm SD & $95 \% \mathrm{Cl}$ & Mean \pm SD & $95 \% \mathrm{Cl}$ & Mean \pm SD & $95 \% \mathrm{Cl}$ & Mean \pm SD & $95 \% \mathrm{Cl}$ & Mean \pm SD & $95 \% \mathrm{Cl}$ & Mean \pm SD & $95 \% \mathrm{Cl}$ \\
\hline All & $0.4 \pm 0.2$ & $0.4-0.5$ & $0.7 \pm 0.3$ & $0.7-0.8$ & $19.8 \pm 5.3$ & $18.4-21.2$ & $15.2 \pm 4.4$ & $14.1-16.4$ & $2.4 \pm 1.1$ & $2.1-2.7$ & $1.5 \pm 1.4$ & $1.1-1.8$ \\
\hline Study group & $0.4 \pm 0.2$ & $0.3-0.5$ & $0.7 \pm 0.3$ & $0.7-0.8$ & $16.5 \pm 2.9$ & $15.5-17.5$ & $14.6 \pm 3.7$ & $13.4-15.9$ & $2.5 \pm 1.0$ & $2.2-2.8$ & $1.4 \pm 1.3$ & $1.0-1.8$ \\
\hline Control group & $0.4 \pm 0.3$ & $0.3-0.5$ & $0.8 \pm 0.3$ & $0.6-0.9$ & $25.8 \pm 2.9$ & $24.5-27.1$ & $16.4 \pm 5.4$ & $13.9-18.9$ & $2.2 \pm 1.4$ & $1.6-2.8$ & $1.6 \pm 1.5$ & $0.9-2.2$ \\
\hline
\end{tabular}


Table 4 Increase in BCVA (Snellen) and reduction in IOP ( $\mathrm{mmHg}$ ) and AGD (numbers), comparing values pre to post phaco-ELT

\begin{tabular}{|c|c|c|c|c|c|}
\hline & & Mean \pm SD & Percentage & Confidence Interval & $P$ Value \\
\hline \multirow[t]{3}{*}{ All eyes } & $\Delta \mathrm{BCVA}$ (post-pre) & $+0.3 \pm 0.3$ & $+80.5 \%$ & $0.3-0.4$ & $p<0.001 *$ \\
\hline & $\Delta \mid \mathrm{IOP}$ (post-pre) & $-4.5 \pm 5.9 \mathrm{mmHg}$ & $-23.0 \%$ & $3.0-6.1$ & $p<0.001 *$ \\
\hline & $\Delta \mathrm{AGD}$ (post-pre) & $-0.9 \pm 1.5$ & $-38.9 \%$ & $0.5-1.3$ & $p<0.001 *$ \\
\hline \multirow[t]{3}{*}{ Study group } & $\triangle \mathrm{BCVA}$ (post-pre) & $+0.3 \pm 0.3$ & $+82.5 \%$ & $0.2-0.4$ & $p<0.001 *$ \\
\hline & $\Delta \mathrm{IOP}$ (post-pre) & $-1.9 \pm 4.4 \mathrm{mmHg}$ & $-11.5 \%$ & $0.4-3.3$ & $p=0.012 *$ \\
\hline & $\Delta \mathrm{AGD}$ (post-pre) & $-1.1 \pm 1.4$ & $-42.9 \%$ & $0.6-1.5$ & $p<0.001 *$ \\
\hline \multirow[t]{3}{*}{ Control group } & $\triangle \mathrm{BCVA}$ (post-pre) & $+0.3 \pm 0.3$ & $+78.6 \%$ & $0.2-0.5$ & $p<0.001 *$ \\
\hline & $\Delta \mathrm{IOP}$ (post-pre) & $-9.5 \pm 5.4 \mathrm{mmHg}$ & $-36.6 \%$ & $6.9-12.0$ & $p<0.001 *$ \\
\hline & $\Delta$ AGD (post-pre) & $-0.7 \pm 1.6$ & $-29.5 \%$ & $0.1-1.4$ & $p=0.085$ \\
\hline
\end{tabular}

Abbreviations: pre before phaco-ELT, post 12 month after phaco-ELT, SD standard deviation, ${ }^{*}$ statistically significant.

The punctal ablation of TM by an excimer laser was first developed and evaluated under laboratory conditions in 1987 by Berlin and colleagues [31,32]. In 1996 results of the technique in humans were published by Vogel et al [16]. Vogel and colleagues used a laser prototype and the laser application was monitored using a contact glass. The ELT technique differs substantially from other minimallyinvasive anti-glaucoma laser techniques like ALT or SLT. The latter techniques induce physical tissue alterations by means of heat or a cellular tissue remodeling, respectively. Because of this the IOP-lowering effect of ALT and SLT reduces over a period of months to years. After ELT, the edges of the laser channels are found to be very smooth $[16,18]$, thus minimizing wound healing and contributing to a longlasting IOP reduction over years.

If it should subsequently be required, filtering surgery is not compromised after ELT because there is no conjunctival manipulation during surgery and therefore no scarring or inflammation of the conjunctiva is induced that would adversely influence the outcome of trabeculectomy. In addition, ELT treats only $90^{\circ}$ of the TM. It is possible to repeat treatment in the remaining three quadrants of the TM when primary treatment is not sufficient.

In a previous study, we showed the success of phacoELT in a smaller collective, who all had a preoperative IOP $>21 \mathrm{mmHg}$ [33]. We found an average IOP decrease of $8.8 \pm 5.3 \mathrm{mmHg}(-34.7 \%, \mathrm{p}<0.001)$, and AGD could be reduced by $0.8 \pm 1.5(-62.7 \%, \mathrm{p}=0.017)$ medications at the same time. This is in accordance with other studies [19-21]. In this study we investigate if phaco-ELT is also a feasible and effective option in patients with lower preoperative IOP.

In the present study, we found a satisfactory IOP reduction in those eyes with lower IOP, although less than that observed in those eyes with higher pre-operative IOP $(-1.9 \mathrm{mmHg},-11.5 \%$ in the study group vs. -9.5 $\mathrm{mmHg},-36.6 \%$ in the control group). This could be explained by the pressure gradient between the anterior chamber and episcleral veins. As episcleral venous pressure is nearly constant, the pressure gradient and the effect of phaco-ELT are directly dependent on IOP.

It is known that, when performed as a single procedure, phacoemulsification has the effect of reducing IOP [34-38]. This is most likely due to the deepening of the chamber angle by extracting the thickened opaque lens and subsequently enhanced drainage of aqueous humor. The IOP reduction following phaco-ELT is greater than that due solely to cataract surgery. Thus, the IOP reduction we found following phaco-ELT is a combined effect of both the phacoemulsification and the ELT. This has also been shown by prior studies comparing ELT alone with phaco-ELT $[20,21]$. Recently the Ocular Hypertension Treatment Study (OHTS) group analyzed their data to assess the IOPlowering effect of cataract extraction. Their cataract group had an IOP comparable to our control group. They found an IOP decrease of $4.1 \mathrm{mmHg}(16.5 \%)$ after cataract extraction, whereas the IOP remained unchanged in their control group of patients who did not undergo cataract extraction. We found an average IOP reduction of $9.5 \mathrm{mmHg}$ (36.6\%) after phaco-ELT. It was also possible to reduce the AGD by an average of 0.7 (29.5\%). The combined effect of Phaco and ELT markedly exceeds that of cataract extraction alone as found by the OHTS group [39]. IOP fluctuation is a risk factor for glaucoma progression. Phacoemulsification may lower IOP but may not have a substantial influence on IOP fluctuation, whereas ELT may reduce diurnal IOP variation. Possible effects on diurnal IOP are an issue worthy of examination in a future study.

We found a success rate of $46.9 \%$ for phaco-ELT after 12 months (62.5\% for the control group). The success rate for the control group is very similar to that previously published and for trabeculectomy by Mills and Khalili et al. [40,41], which is remarkable considering the minimally invasive nature of this technique. However, success rates after trabeculectomy are mostly reported 
Table 5 Dropouts due to IOP-lowering surgery during follow up

\begin{tabular}{|c|c|c|c|c|c|c|c|c|c|c|c|c|c|c|c|}
\hline $\begin{array}{l}\text { Study- } \\
\text { no. }\end{array}$ & $\begin{array}{l}\text { Date } \\
\text { of } \\
\text { birth }\end{array}$ & Gender & Eye & Diagnosis & $\begin{array}{l}\text { BCVA } \\
\text { pre } \\
\text { phaco- } \\
\text { ELT }\end{array}$ & $\begin{array}{l}\text { IOP } \\
\text { pre } \\
\text { phaco- } \\
\text { ELT }\end{array}$ & $\begin{array}{l}\text { AGD } \\
\text { pre } \\
\text { phaco- } \\
\text { ELT } \\
\end{array}$ & $\begin{array}{l}\text { Subsequent } \\
\text { surgery }\end{array}$ & $\begin{array}{l}\text { Time to } \\
\text { Subsequent } \\
\text { surgery } \\
\text { [month] }\end{array}$ & $\begin{array}{l}\text { BCVA pre } \\
\text { Subsequent } \\
\text { surgery }\end{array}$ & $\begin{array}{l}\text { IOP pre } \\
\text { Subsequent } \\
\text { surgery }\end{array}$ & $\begin{array}{l}\text { AGD pre } \\
\text { Subsequent } \\
\text { surgery }\end{array}$ & $\begin{array}{l}\text { BCVA 1-3 } \\
\text { month after } \\
\text { Subsequent } \\
\text { surgery }\end{array}$ & $\begin{array}{l}\text { IOP 1-3 } \\
\text { month after } \\
\text { Subsequent } \\
\text { surgery }\end{array}$ & $\begin{array}{l}\text { AGD 1-3 } \\
\text { month after } \\
\text { Subsequent } \\
\text { surgery }\end{array}$ \\
\hline 55 & $\begin{array}{l}15 / \\
07 / \\
1941\end{array}$ & $\mathrm{~F}$ & RE & PEX & 0.1 & 19 & 3 & $5 \times C P C$ & 0.9 & 0.3 & 30 & 4 & 0.3 & 10 & 2 \\
\hline 70 & $\begin{array}{l}08 / \\
09 / \\
1930\end{array}$ & $\mathrm{~F}$ & RE & PEX & $\mathrm{HM}$ & 20 & 4 & TE, SLT & 3.5 & 0.6 & 30 & 1 & 0.4 & 28 & 4 \\
\hline 38 & $\begin{array}{l}06 / \\
10 / \\
1927\end{array}$ & M & RE & PEX & 0.2 & 23 & 3 & TE & 4.9 & 0.5 & 30 & 3 & 0.4 & 10 & 0 \\
\hline 12 & $\begin{array}{l}28 / \\
10 / \\
1934\end{array}$ & $\mathrm{~F}$ & LE & PEX & 0.2 & 24 & 2 & $C P C$ & 1.9 & 0.1 & 32 & 1 & 0.1 & 23 & 1 \\
\hline 65 & $\begin{array}{l}14 / \\
05 / \\
1947\end{array}$ & M & LE & POAG & 0.6 & 33 & 1 & $4 \times C P C, T E$ & 1.1 & 0.1 & 34 & 4 & 0.1 & 15 & 1 \\
\hline 42 & $\begin{array}{l}14 / \\
01 / \\
1940\end{array}$ & $\mathrm{~F}$ & LE & PEX & 0.4 & 36 & 4 & $C P C$ & 0.9 & 0.5 & 30 & 5 & 0.6 & 18 & 1 \\
\hline 49 & $\begin{array}{l}11 / \\
01 / \\
1935\end{array}$ & $\mathrm{~F}$ & LE & PEX & 0.1 & 17 & 3 & $\begin{array}{l}\text { CPC, 1x TA-IVI, 4x } \\
\text { Avastin-IVI (due to } \\
\text { Irvine-Gass } \\
\text { syndrome) }\end{array}$ & 4.5 & 0.3 & 14 & 2 & 0.1 & 15 & 2 \\
\hline
\end{tabular}


without AGD whereas our success rates are with or without AGD. After trabeculectomy, local antiglaucamatous medication would potentially compromise the long-term efficacy of the filtering bleb by inducing inflammation and scarring. After phaco-ELT, topical medications may be applied without such a risk. Therefore, we do not classify medical treatment after phaco-ELT as a treatment failure as long as the number of medications is equal or less compared to the preoperative number.

A weakness of our study is the absence of a group undergoing only phacoemulsification, to act as a further control. The IOP-lowering effect of phaco has been widely investigated. We are currently engaged in a study following patient outcomes over five years and longer. Included in this study are patients with a range of glaucomas with different pathological mechanisms. The TM, especially the juxtacanalicular region of TM, is known to have the highest aqueous outflow resistance. This is the major cause of elevated IOP in primary open angle glaucoma. ELT bypasses this outflow pathway, as the aqueous humor is guided directly from the anterior chamber into the collector channels. Therefore, the underlying mechanism of the glaucoma is irrelevant as long as the elevated IOP is caused by an elevated outflow resistance in the TM.

\section{Conclusion}

For a selected collective of glaucoma or ocular hypertensive patients with at least a moderate cataract and who do not need the lowest target pressures, and in particular for those with an IOP over $21 \mathrm{mmHg}$, the combined surgery of excimer laser trabeculotomy and phacoemulsification (phacoELT) seems to be a good way to avoid or at least to delay trabeculectomy for some years. For patients with an IOP of $21 \mathrm{mmHg}$ or lower, the addition of ELT to a standard cataract surgery procedure is a good option to lower IOP and to save AGD.

\section{Competing interests}

The authors report no conflicts of interest. The authors alone are responsible for the content and writing of the paper. No financial support was received.

\section{Authors' contributions}

MTH, JVMH and JF contributed to the study design, the data analysis, interpretation of the data, the discussion, and manuscript writing. MTH and JF contributed to ophthalmologic data collection. All three authors read and approved the final manuscript.

\section{Financial disclosure}

No author has a financial or proprietary interest in any material or method mentioned. The study is registered in the clinical trials registry of the U.S. National Institutes of Health (NCT01194310). The manuscript has not been presented at a meeting before.

Received: 27 November 2012 Accepted: 7 June 2013

Published: 24 June 2013

\section{References}

1. Heijl A, Leske MC, Bengtsson B, Hyman L, Hussein M: Reduction of intraocular pressure and glaucoma progression: results from the Early Manifest Glaucoma Trial. Arch Ophthalmol 2002, 120(10):1268-1279.

2. Grant WM, Burke JF Jr: Why do some people go blind from glaucoma? Ophthalmology 1982, 89(9):991-998.

3. Collaborative Normal-Tension Glaucoma Study Group: The effectiveness of intraocular pressure reduction in the treatment of normal-tension glaucoma. Am J Ophthalmol 1998, 126(4):498-505.

4. Collaborative Normal-Tension Glaucoma Study Group: Comparison of glaucomatous progression between untreated patients with normaltension glaucoma and patients with therapeutically reduced intraocular pressures. Am J Ophthalmol 1998, 126(4):487-497.

5. The AGIS Investigators: The Advanced Glaucoma Intervention Study (AGIS): 7. The relationship between control of intraocular pressure and visual field deterioration. Am J Ophthalmol 2000, 13(4):429-440.

6. Palmberg P: Risk factors for glaucoma progression: Where does intraocular pressure fit in? Arch Ophthalmol 2001, 119(6):897-898.

7. Cairns JE: Trabeculectomy. Preliminary report of a new method. Am J Ophthalmol 1968, 66(4):673-679.

8. Singh K, Mehta K, Shaikh NM, Tsai JC, Moster MR, Budenz DL, Greenfield DS, Chen PP, Cohen JS, Baerveldt GS, et al: Trabeculectomy with intraoperative mitomycin C versus 5-fluorouracil. Prospective randomized clinical trial. Ophthalmology 2000, 107(12):2305-2309.

9. Bill A, Svedbergh B: Scanning electron microscopic studies of the trabecular meshwork and the canal of Schlemm-an attempt to localize the main resistance to outflow of aqueous humor in man. Acta Ophthalmol (Copenh) 1972, 50(3):295-320.

10. Maepea $O$, Bill A: Pressures in the juxtacanalicular tissue and Schlemm's canal in monkeys. Exp Eye Res 1992, 54(6):879-883.

11. Vogel MH, Schildberg P: [Histological findings after experimental lasertrabeculo-puncture (author's transl)]. Klin Monbl Augenheilkd 1973, 163(3):353-358.

12. Kaufmann R, Hibst R: Pulsed Er: YAG- and $308 \mathrm{~nm}$ UV-excimer laser: an in vitro and in vivo study of skin-ablative effects. Lasers Surg Med 1989, 9(2):132-140.

13. Muller-Stolzenburg N, Muller GJ: Transmission of $308 \mathrm{~nm}$ excimer laser radiation for ophthalmic microsurgery-medical, technical and safety aspects. Biomed Tech (Berl) 1989, 34(6):131-138.

14. Vogel M, Scheurer G, Neu W, Dressel M, Gerhardt H: [Ablation of the trabecular meshwork]. Klin Monbl Augenheilkd 1990, 197(3):250-253.

15. Jahn R, Lierse W, Neu W, Jungbluth KH: Macroscopic and microscopic findings after excimer laser treatment of different tissue. J Clin Laser Med Surg 1992, 10(6):413-418.

16. Vogel M, Lauritzen $\mathrm{K}$, Quentin CD: [Targetted ablation of the trabecular meshwork with excimer laser in primary open-angle glaucoma]. Ophthalmologe 1996, 93(5):565-568

17. Vogel M, Lauritzen K: [Selective excimer laser ablation of the trabecular meshwork. Clinical results]. Ophthalmologe 1997, 94(9):665-667.

18. Walker $\mathrm{R}$, Specht $\mathrm{H}$ : [Theoretical and physical aspects of excimer laser trabeculotomy (ELT) ab interno with the AIDA laser with a wave length of $308 \mathrm{~mm}$ ]. Biomed Tech (Berl) 2002, 47(5):106-110.

19. Babighian S, Rapizzi E, Galan A: Efficacy and safety of ab interno excimer laser trabeculotomy in primary open-angle glaucoma: two years of follow-up. Ophthalmologica 2006, 220(5):285-290.

20. Pache M, Wilmsmeyer S, Funk J: [Laser surgery for glaucoma: excimerlaser trabeculotomy]. Klin Monbl Augenheilkd 2006, 223(4):303-307.

21. Wilmsmeyer S, Philippin H, Funk J: Excimer laser trabeculotomy: a new, minimally invasive procedure for patients with glaucoma. Graefes Arch Clin Exp Ophthalmol 2006, 244(6):670-676.

22. Herdener S, Pache M: [Excimer laser trabeculotomy: minimally invasive glaucoma surgery]. Ophthalmologe 2007, 104(8):730-732.

23. Taliaferro K: Excimer laser trabeculotomy. Ophthalmologica 2008, 222(6):424.

24. Babighian S, Caretti L, Tavolato M, Cian R, Galan A: Excimer laser trabeculotomy vs 180 degrees selective laser trabeculoplasty in primary open-angle glaucoma. A 2-year randomized, controlled trial. Eye (Lond) 2010, 24(4):632-638.

25. Shaffer RN: A suggested anatomic classification to define the pupillary block glaucomas. Invest Ophthalmol 1973, 12(7):540-542.

26. Holladay JT: Visual acuity measurements. J Cataract Refract Surg 2004 30(2):287-290 
27. Holladay JT, Prager TC: Mean visual acuity. Am J Ophthalmol 1991, 111(3):372-374

28. Gedde SJ, Schiffman JC, Feuer WJ, Parrish RK 2nd, Heuer DK, Brandt JD: The tube versus trabeculectomy study: design and baseline characteristics of study patients. Am J Ophthalmol 2005, 140(2):275-287.

29. Huang S, Yu M, Feng G, Zhang P, Qiu C: Histopathological study of trabeculum after excimer laser trabeculectomy ab interno. Yan Ke Xue Bao 2001, 17(1):11-15.

30. Neuhann T, Scharrer A, Haefliger E: Excimer laser trabecular ablation ab interno (ELT) in the treatment of chronic open-angle glaucoma. A pilot study. Ophthalmo-Chirurgie 2001, 13:3-7.

31. Berlin MS, Rajacich G, Duffy M, Grundfest W, Goldenberg T: Excimer laser photoablation in glaucoma filtering surgery. Am J Ophthalmol 1987, 103(5):713-714.

32. Berlin MS, Yoo PH, Ahn RJ: The role of laser sclerostomy in glaucoma surgery. Curr Opin Ophthalmol 1995, 6(2):102-114.

33. Toteberg-Harms M, Ciechanowski PP, Hirn C, Funk J: [One-year results after combined cataract surgery and excimer laser trabeculotomy for elevated intraocular pressure]. Ophthalmologe 2011, 108(8):733-738.

34. Shingleton BJ, Gamell LS, O'Donoghue MW, Baylus SL, King R: Long-term changes in intraocular pressure after clear corneal phacoemulsification: normal patients versus glaucoma suspect and glaucoma patients. J Cataract Refract Surg 1999, 25(7):885-890.

35. Hudovernik M, Pahor D: Intraocular pressure after phacoemulsification with posterior chamber lens implantation in open-angle glaucoma. Klin Monbl Augenheilkd 2003, 220(12):835-839.

36. Kim DD, Doyle JW, Smith MF: Intraocular pressure reduction following phacoemulsification cataract extraction with posterior chamber lens implantation in glaucoma patients. Ophthalmic Surg Lasers 1999, 30(1):37-40.

37. Dooley I, Charalampidou S, Malik A, Loughman J, Molloy L, Beatty S: Changes in intraocular pressure and anterior segment morphometry after uneventful phacoemulsification cataract surgery. Eye (Lond) 2010 24(4):519-526. quiz 527.

38. Shrivastava A, Singh K: The effect of cataract extraction on intraocular pressure. Curr Opin Ophthalmol 2010, 21(2):118-122.

39. Mansberger SL, Gordon MO, Jampel H, Bhorade A, Brandt JD, Wilson B, Kass MA: Reduction in Intraocular Pressure after Cataract Extraction: The Ocular Hypertension Treatment Study. Ophthalmology 2012, 11(9):1826-31.

40. Mills KB: Trabeculectomy: a retrospective long-term follow-up of 444 cases. Br J Ophthalmol 1981, 65(11):790-795.

41. Khalili MA, Diestelhorst M, Krieglstein GK: [Long-term follow-up of 700 trabeculectomies]. Klin Monbl Augenheilkd 2000, 217(1):1-8. discussion 9.

doi:10.1186/1471-2415-13-24

Cite this article as: Töteberg-Harms et al: Cataract Surgery combined with excimer laser trabeculotomy to lower intraocular pressure: effectiveness dependent on preoperative IOP. BMC Ophthalmology 2013 13:24

\section{Submit your next manuscript to BioMed Central and take full advantage of:}

- Convenient online submission

- Thorough peer review

- No space constraints or color figure charges

- Immediate publication on acceptance

- Inclusion in PubMed, CAS, Scopus and Google Scholar

- Research which is freely available for redistribution 